\title{
eMMI (e-MODULE MULTIPLE INTELLIGENCE) : MODUL FISIKA DASAR MAHASISWA DENGAN 3D PAGEFLIP PRO
}

\author{
${ }^{1}$ Khoirun Nisa*, ${ }^{2}$ Ismi Nurul, ${ }^{3}$ Mistianah \\ ${ }^{123}$ Program Studi Pendidikan Biologi, IKIP Budi Utomo Malang \\ e-mail: khoirunisaq@gmail.com*
}

\begin{abstract}
This study aims to produced eMMI based on multiple intelligence (eMMI) with 3D pageflip pro for biology student's in IKIP Budi Utomo Malang, in the circulatory system material that is suitable for used in the learning process. This research was developed with a 4-D model consisting of definitions, planning, development and dissemination. Data collection using a questionnaire. This eMMI have been validated by material experts and media experts.The evaluation results from material validation, is known that above $90 \%$, while the results of media validation are above $96 \%$. Small scale test results indicate the validity results above $90 \%$. From the results of the validation of media experts and material experts, it is stated that the e-eMMIe is suitable for use and based on the questionnaire, it can be said that students and teachers are expected to really take advantage of teaching materials in order to create interesting and fun learning in physics learning.
\end{abstract}

Keywords: eMMI; basic physics; multiple intelligence

\begin{abstract}
ABSTRAK
Penelitian ini bertujuan untuk menghasilkan e-MMI berbasis multiple intelligence (eMMI) dengan 3D pageflip pro bagi mahasiswa biologi di IKIP Budi Utomo Malang, dalam materi sistem peredaran darah yang layak digunakan dalam proses pembelajaran. Penelitian ini dikembangkan dengan model 4-D yang terdiri dari definisi, perencanaan, pengembangan dan diseminasi. Pengumpulan data menggunakan kuesioner. eMMI ini telah divalidasi oleh ahli materi dan ahli media. Hasil evaluasi dari validasi materi, diketahui di atas $90 \%$, sedangkan hasil validasi media di atas $96 \%$. Hasil uji skala kecil menunjukkan hasil validitas di atas $90 \%$. Dari hasil validasi ahli media dan ahli materi dinyatakan eMMI layak digunakan dan berdasarkan angket dapat dikatakan siswa dan guru diharapkan benar-benar memanfaatkan bahan ajar agar dapat untuk menciptakan pembelajaran yang menarik dan menyenangkan dalam pembelajaran fisika.
\end{abstract}

Kata kunci: pendekatan berbasis genre; keterampilan menulis; karya siswa

\section{PENDAHULUAN}

IKIP Budi Utomo sebagai salah satu PT di Kota Malang yang terus berinovasi dalam usaha untuk meningkatkan kualitas dalam pembelajaran, dimana dibutuhkan beberapa perubahan dan penyesuaian untuk dapat mengikuti perkembangan dan pemanfaatan teknologi. Salah satunya dengan menerapkan perkuliahan berbasis IT dan konsep paperless dalam setiap kegiatan pembelajarannya. Sejalan dengan hal tersebut, pada salah satu matakuliah di Program Studi Pendidikan Biologi yaitu

Cara mengutip: Nisa, K., Nurul, I. \& Mistianah (2021). eMMI (e-Module Multiple Intelligence : Modul Fisika Dasar Mahasiswa dengan 3D Pageflip Pro. Inteligensi: Jurnal Ilmu Pendidikan, 4(1), 67-72 
matakuliah Fisika Dasar, tugas maupun tes yang diberikan sudah berbasis online. Mahasiswa diminta meng-upload tugas individu maupun kelompoknya ke forum atau platform yang telah disiapkan oleh pihak institusi. Hal ini membuktikan bahwa teknologi sudah terintegrasi dengan baik dalam bidang Pendidikan, khususnya di lingkungan IKIP Budi Utomo. Mahasiswa sudah mulai terbiasa belajar, mencari sumber literatur, dan menemukan solusi atas permasalahan secara online. Oleh karena itu diperlukan suatu upaya untuk menarik minat melalui efisiensi suatu media yang selaras dengan teknologi (Said et al., 2018; Wallner \& Wagner, 2016), sehingga perlu adanya kreativitas dan inovasi lebih lanjut dari para dosen agar dapat penunjang kegiatan pembelajaran yang sesuai dengan perkembangan era 4.0 dan sesuai dengan tingkat kompetensi mahasiswa (Nisa \& Denny, 2018). Salah satunya dengan pengembangan media eMMI (e-Module Multiple Intelligence) dengan 3D PageFlip Pro. Dengan model pengembangan 4D meliputi tahap pendefinisian (define), tahap perancangan (design), tahap pengembangan (develop), dan tahap penyebarluasan (disseminate) yang kemudian berupa saran maupun kritik yang terdapat pada instrumen validasi sedangkan data kuantitatif berupa data skor validasi yang dikoversi dalam bentuk persentase penilaian.

\section{METODE PENELITIAN}

Penelitian ini merupakan 4D dari Thiagarajan (1974) yang teridiri dari tahap Define, Design, Develop dan Disseminate. Pertama, dilakukan penetapan dan pendefinisian syarat-syarat pembelajaran. Selanjutnya dengan merancang perangkat pembelajaran. Tahap develop dilakukan untuk menghasilkan produk yang sudah dirancang. Terakhir, tahap diseminasi untuk menyebarkan produk kelompok, atau system. Data pada penelitian ini berupa data hasil validasi dari ahli materi maupun ahli media yang kemudian dijadikan acuan untuk kelayakan e-MMI yang sudah dibuat.

\section{HASIL DAN PEMBAHASAN}

Penelitian dilakukan sesuai dengan model pengembangan 4D, dimana tahap define memiliki 5 tahap utama yaitu frontend analysis, learner analysis, task analysis, concept analysis dan specifying instructional objectives. Front-end analysis dilakukan untuk mengetahui kesulitan/ hambatan yang dialami oleh mahasiswa dalam memahami Mata kuliah Fisika Dasar, mahasiswa mengalami kesulitan dalam mempelajari Ilmu fisika dikarenakan Materi yang tidak kontekstual sehingga mahasiswa dan bersifat luas sehingga perlu adanya penggambaran materi yang sesuai kontekstual yang bias diaplikasikan dalam kehidupan sehari hari selain itu perlu adanya beberapa tampilan video pembelajaran atap pelaksanaan embelajarn yang langsung diaplikasikan ke kegiatan sehari hari dan perlu adanya EMMI/buku ajar yang interaktif untukk memenuhi kebutuhan mahasiswa. Learner analysis dilaksanakan dengan pengisian angket Sebaran Multiple Intelligence (HGMI-Test) oleh seluruh mahasiswa Pendidikan Biologi Angkatan 2016 dan 2017 di IKIP Budi Utomo Malang, kemudian data dibedakan berdasarkan gender. Data terdiri dari 122 dengan 92 data perempuan dan 30 laki laki. Kemudian dilakukan uji normalitas dan uji 
Kolomogrov Smirnov. Hasil uji Normalitas menunjukkan data tidak terdisribusi normal sehingga dilakukan Uji U Mann-Whitney, dimana dari 9 kecerdasan Majemuk hanya terdapat 1 kecerdasan yang mempunyai pengaruh/ perbedaan antara gender terhadap Kecerdasan Linguistik, kita tahu kecerdasan linguistic merupakan kemampuan seseorang dalam menggunakan kata secara tepat baik lisan maupun tulisan (Amri, 2019) yang menyatakan siswa perempuan menggunakan lebih banyak jumlah kata, jumlah kata kerja, jumlah kalimat (termasuk kalimat verbal dan non-verbal, tunggal dan jamak) dibandingkan siswa laki-laki.

Secara umum dapat dikatakan bahwa tidak ada hubungan atau perbedaan antara gender terhadap kecerdasan majemuk yang dimiliki oleh mahasiswa, hal ini juga disampaikan oleh (Jatmika, 2014). Ada beberapa fakta yang menyebabkan tidak adanya pengaruh/ perbedaan gender terhadap Kecerdasan majemuk mahasiswa diantaranya: 1) sebagian besar Mahasiswa IKIP Budi Utomo Malang berasal dari daerah yang sama; 2) usia mahasiswa yang hampir sama; 3) adanya kesamaan kesempatan dalam pembelajaran antara laki laki dan wanita. Pada tahap concept analysis, dilakukan beberapa hal berikut yaitu: 1) mengidentifikasi konsep yang akan diajarkan, 2) menyusun dan merinci indikator serta tujuan pembelajaran. Selanjutnya pada tahap Task analysis diidentikfikasi keterampilan-keterampilan yang akan diteliti untuk kemudian di integrasikan ke dalam eMMI. Tahap design terdiri dari empat langkah, yaitu: (1) penyusunan standar tes (criterion-test construction yang dilakukan dengan menyusun tes acuan/patokan dalam validasi media dan materi pembelajaran. Selain itu ditentukan juga tes acuan keterlaksanaan media dalam pembelajaran, (2) pemilihan media (media selection) yang sesuai, (3) pemilihan format (format selection), (4) membuat rancangan awal (initial design). Pada tahap penyusunan criterion test. Produk yang dikembangkan adalah eEMMI Multiple Intelligence untuk mata kuliah Fisika dasar pada materi Fulida Statis dan Dinamis. eEMMI ini nantinya digunanakan untuk Penunjang Pada saat perkuliahan sehaingga dapat mempermudah proses pembelajaran. EMMI yang diperoleh pada tahap awal menunjukkan beberapa bagian seperti linguistik, logika, musikal, kinestetik, intrapersonal, naturalis hingga eksistensi. Beberapa bagian dari eMMI disajikan pada gambar 1 berikut.
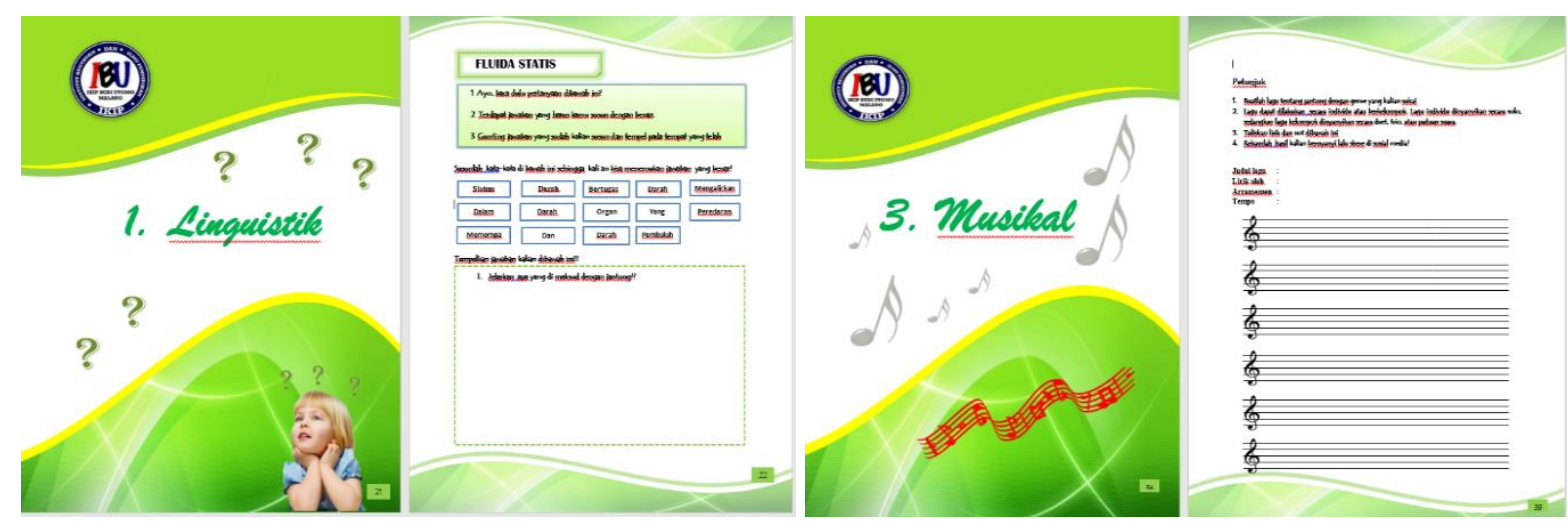


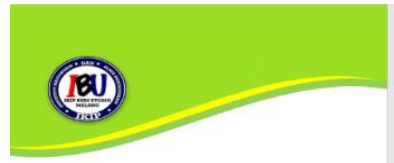

6. Intrapersonal

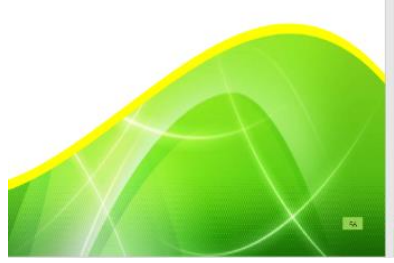

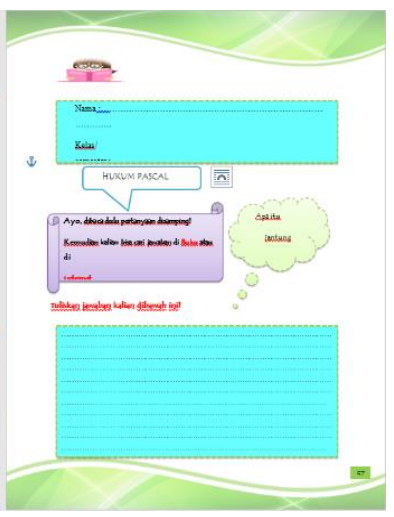

Gambar 1. Tampilan eMMI Multiple Intelligence

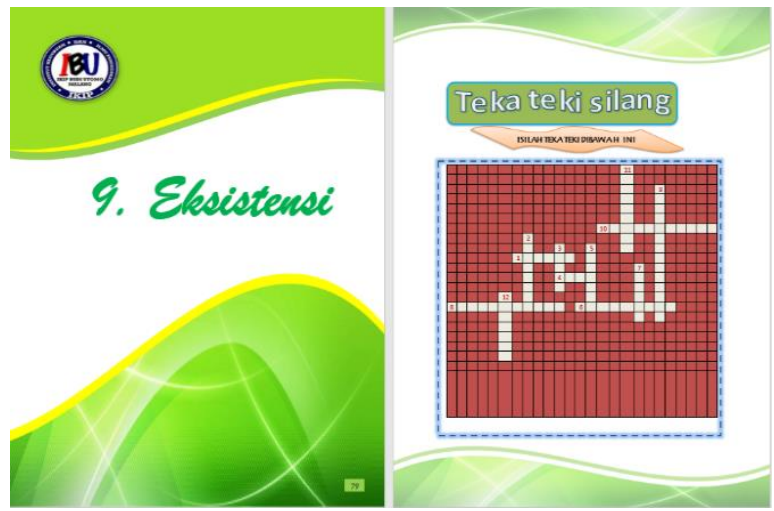

Pada tahap selanjutnya dilakukan tahap Develop, yaitu tahap validasi ahli media dan materi, serta uji keterbacaan oleh mahasiswa yang telah menempuh matakuliah Fisika Dasar. Selain itu dilakukan uji coba terbatas pada 10 mahasiswa yang belum menempuh mata kuliah Fisika Dasar untuk mengetahui efektifitas penerapannya dimana hasil validasi ahli materi disajikan pada tabel 1 berikut.

\section{Tabel 1. Hasil Validasi ahli materi}

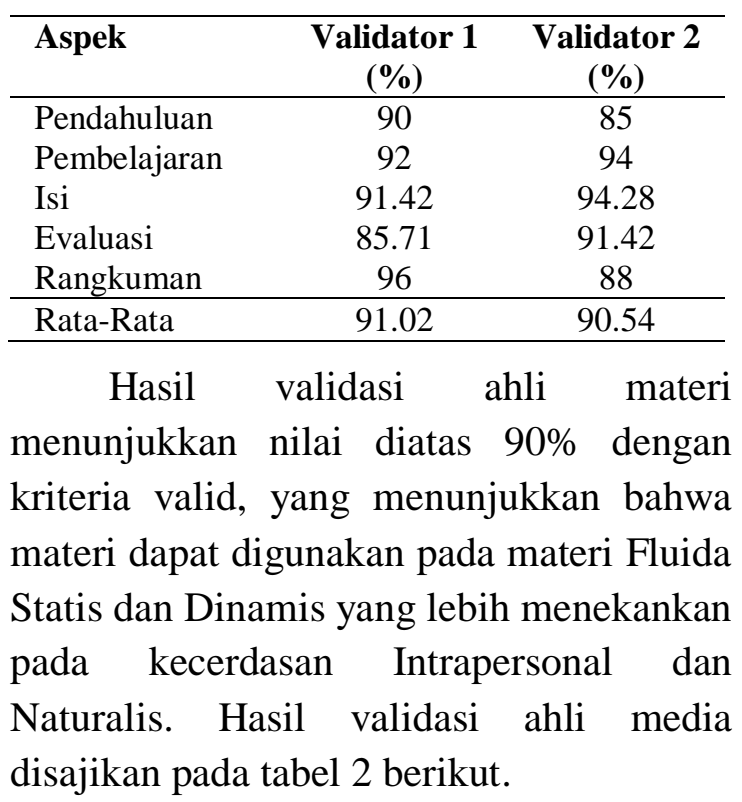

Tabel 2. Hasil Validasi ahli media

\begin{tabular}{ccc}
\hline Aspek & $\begin{array}{c}\text { Validator 1 } \\
(\boldsymbol{\%})\end{array}$ & $\begin{array}{c}\text { Validator } \\
\mathbf{2}(\boldsymbol{\%})\end{array}$ \\
\hline Fisik & 95.56 & 91.11 \\
Pendahuluan & 100 & 100 \\
Pembelajaran & 100 & 96 \\
Struktur & 100 & 100 \\
Tugas & 100 & 95 \\
Rangkuman & 100 & 96 \\
\hline Rata-Rata & 99.25 & 96.35 \\
\hline
\end{tabular}

Hasil menunjukkan nilai diatas $96 \%$ yang berarti eMMI sudah baik dalam aspek fisik, pendahuluan, pembelajaran, struktur, tugas dan rangkuman, dan sudah layak digunakan untuk materi Fluida Statis dan Dinamis. eMMI diharapkan dapat mempermudah mempelajari materi Fluida. Hal ini dapat dikatakan mampu membantu pendidik dan peserta didik karena produk pengembangan ini dapat mempengaruhi tingkat ketertarikan dan motivasi mahasiswa, selain itu juga membantu mahasiswa mengolah informasi dengan lebih baik (Anantyarta \& Sari, 2017) yang menyatakan bahwa media pembelajaran yang baik adalah yang mampu mempermudah pendidik serta. Selain itu mampu meningkatkan aktivitas yang interaktif karena kombinasi dari grafik, gambar dan elemen animasi yang disajikan (Aldya \& Arifendi, 2021), meningkatnya aktivitas pada satu jenis topik dapat 
memiliki kekuatan untuk membuat siswa mau meluangkan waktunya untuk berpikir, berdialog, dan menciptakan ide (McCarthy, 2014; Amjah, 2014).

\section{SIMPULAN}

Pengembangan eMMI (e-Module Multiple Intelligence) untuk mata kuliah fisika Dasar dianggap telah tervalidasi dengan sangat baik pada aspek media dan materi. Berdasarkan hasil validasi materi diketahui diatas 90\%, sedangkan hasil validasi media diatas $96 \%$. Hasil uji skala kecil menunjukkan adanya hasil validitas diatas 90\%. Berdasarkan hasil diseminasi, secara umum sudah baik dan diharapkan dapat diaplikasikan dalam pembelajaran.

\section{DAFTAR PUSTAKA}

Aldya, R. F., \& Arifendi, R. F. (2021). Botanical application: Androidbased learning media to enhance interest in learning plant material. Edubiotik: Jurnal Pendidikan, Biologi Dan Terapan, 6(01), 17-25. https://doi.org/10.33503/ebio.v6i01.1 246

Amjah, D. Y. P. H. (2014). A Study of Teachers' Strategies so Develop Students' Interest towards Learning English as a Second Language. Procedia - Social and Behavioral Sciences, 134, 188-192. https://doi.org/10.1016/j.sbspro.2014 .04 .238

Anantyarta, P \& Sari, RLI. (2017). Pengembangan Media Auto Play dengan MetodeMeans Ends Analysis (MEA) pada Matakuliah Genetika. Makalah disajikan dalam Seminar Pendidikan IPA Pascasarjana UM

Amri, Z. (2019). Perbedaan Bahasa Siswa Laki-Laki Dan Siswa Perempuan: Sebuah Studi Kasus Di Kelas V Sdn 09 Air Tawar Barat Padang Sumatera Barat. Lingua Didaktika:
Jurnal Bahasa Dan Pembelajaran

Bahasa, 3(1), 96. https://doi.org/10.24036/ld.v3i1.737 1

Jatmika, D. (2014). Hubungan Antara Kecerdasan Intelektual Dengan Produktivitas Kerja Pada Mahasiswa Baru Fakultas Ilmu Sosial Dan Humaniora .... Psibernetika, 7(1), 51-64.

https://journal.ubm.ac.id/index.php/p sibernetika/article/view/509/477

McCarthy, J. (2014). Learner interest matters: Strategies for empowering student choice. Retrieved from https://www.edutopia.org/blog/differ entiated-instruction-learner-interestmatters-john-mccarthy

Musfiroh, T. (2014). "Multiple Intelligences dan Implikasinya dalam Pendidikan". Pusdi PAUD. Lemlit UNY, http//multipleintelegence.com diakses tanggal 15 Oktober 2014

Nisa \& Deny, S. (2018). Pengembangan Modul Interaktif berbasis Multiple Intelligence dengan Autoplay pada konsep Perubahan Materi Genetik di IKIP Budi Utomo Malang, Jurnal Edubiotik Edisi September 2018 Vol. 3, No. 2 : Hal $30-36$ (http://ejurnal.budiutomomalang.ac.i d/index.php/edubiotik/article/view/1 68).

Said, K., Kurniawan, A., \& Anton, O. (2018). Development of media-based learning using android mobile learning. Journal of Theoretical and Applied Information Technology, 96(3), 668-676

Thiagarajan, S., Semmel, D. S \& Semmel, M. I. 1974. Instructional Development for Training Teachers of Expectional Children. (http://www.eric.ed.gov/, diakses 1 Maret 2012)

Wigfield, A., \& Cambria, J. (2010). Students' achievement values, goal orientations, and interest: definitions, 
development, and relations to

Developmental Review, 30(1), 1-35.

achievement outcomes. 